\title{
Revisitando a relação entre museu e comunicação
} Mary Weinstein ${ }^{1}$

Resumo: Este trabalho busca enfocar a relação entre museu e comunicação, no que tange à publicização de propostas, atividades e agendamento da própria instituição. Tratamos de jornalismo, da opinião pública e da premência de que o museu seja notícia o bastante, entre tantos assuntos que são agendados pelos meios de comunicação, para poder se colocar na mídia. Reconhecemos que o museu em si é um agendador que selecionou o objeto de memória, de arte, ou de qualquer outra natureza, para publicizar, destacar, salientar e colocar em evidência, sendo, portanto, também, um mediador. Então, esta permeabilização da mídia pela seleção que o museu faz se torna um meta agendamento que confirma as escolhas feitas para plasmar a realidade, para valorizar e destacar na sociedade. Para problematizar estes aspectos, recorremos à Teoria da Agenda Setting, ao conceito de opinião pública de Walter Lippman e à constatação de que há uma necessidade de publicizar o patrimônio cultural. Como universo empírico, selecionamos dez museus situados em Salvador, na Bahia.

Palavras-chave: Museu, Agendamento, Jornalismo, Patrimônio Cultural.

Abstract: This work is about the relation between museum and communication, concerning to the publicity of proposals, activities and scheduling of the own institution. It deals with journalism, public opinion and the need for the museum to be newsworthy, among so many issues that are scheduled by the media, to be able to position itself in the media.

\footnotetext{
${ }^{1}$ Professora adjunta do Curso de Comunicação/Jornalismo da Universidade Estadual do Sul da Bahia (Uesb) e do Programa de Pós-Graduação em Museologia (PPGMuseu) da Universidade Federal da Bahia (UFBA).
} 
The museum itself is a scheduler that selects the object of memory, art, or any other nature to publicize, highlight, emphasize and bring forward, and is therefore also a mediator. So, this permeabilization of the media by the selection that the museum makes becomes a meta-schedule that confirms the choices made to approach the reality, to value and to stand out in the society. In order to problematize these aspects, we use the Agenda-Setting Theory, the concept of public opinion of Walter Lippman and the understanding that there is a need to publicize the cultural patrimony. As an empirical universe, we selected ten museums located in Salvador, Bahia.

Keywords: Museam, Agenda Setting, Journalism, Cultural Patrimony.

\section{Introdução}

Este trabalho tem como foco a relação entre a instituição museu, como espaço discursivo, e as potencialidades de ampliação da recepção e dos efeitos que podem ocorrer no seu território. Não tratamos, particularmente, da ação, nem de efeitos, mas do fato de que o museu, como construção e produção de sentidos e significados, pressupõe interação direta com os seus fruidores, sem intermediadores, como os das transposições digitais. Partimos do entendimento de que, para que a integração se estabeleça, necessita-se de público in loco. Assim, o museu, ele próprio mediador, se habilita a propor uma agenda. Também, como parte desta reflexão, está a publicização dessas suas ações, que passa pelos veículos de comunicação formais, estes, assumidamente, mediadores. Buscamos dez instituições museais situadas em Salvador, na Bahia, para comprovar o pressuposto de que a comunicação contribui para a aproximação do público.

Museu, em sua forma tradicional e ainda tão comum na contemporaneidade, situa-se em local específico, em um determinado endereço. Dentro dele, onde se encontra a exposição de objetos e temas, ações são desenvolvidas, visando a participação da comunidade e tendo como foco questões de interesse público. 0 museu se completa e se torna íntegro, com a presença de visitantes. Assim como acontece em todas as artes, é preciso que o 
museu seja lido, experienciado. Eco (1968) se refere à experiência como requisito para o estabelecimento da relação com o objeto, sendo a integração positiva ou negativa. O autor discorre sobre variados aspectos, inclusive, sobre a questão da utilização da máquina pelo homem como uma extensão dele, dos seus sentidos. Eco fala de uma nova poética de sobrevivência que se encaixa a uma vida integrada às tecnologias.

O autor considera a experiência uma premissa para que ocorra a interatividade, a compreensão, o entendimento do homem com o que Ihe cerca. Essa experiência se constitui em contraponto, diferenciando a interação que se processa com a mediação dos meios de comunicação eletrônicos, que, praticamente, em qualquer ambiente, podem ser acessados. 0 interlocutor interage, seja em silêncio, seja em situação estática, seja em trânsito. A autocomunicação se desenvolve como a condição que a plataforma tecnológica oferece ao dar suporte à construção da autonomia do ator social (Castells, 2013).

Diversamente da relação que se sustenta com os acessos meramente virtuais à distância, e para que o museu exerça a sua função, o visitante terá que se transportar fisicamente até o endereço em que vivenciará a experiência que a instituição museu propõe. Esta forma de acesso - visitação - ao conteúdo e à forma do museu o destaca de outras realidades no campo da arte e da cultura, na contemporaneidade, tornando-o único. E o preserva do jeito que foi em outras épocas, mesmo que o seu conteúdo e a sua relação com o todo e com o além museu tenham mudado e que agora o museu seja devidamente identificado como aberto. 0 museu não é fechado porque tem e oferece infinitas possibilidades de interação, em especial, a interação pessoal que se mantém imprescindível.

$\mathrm{Na}$ maior parte da história da comunicação jornalística, houve - e ainda há - ameaças à integridade do jornalista, do tipógrafo ou do editor (McQuail, 2003), especialmente quando se encontram conflitos de interesse a partir do que é publicado. No jornal, a informação é sempre em torno de fatos que são 
novidades. No jornalismo, a novidade é um dos valores-notícia (Galtung \& Ruge, 1965) mais considerados. Nos museus, a comunicação dificilmente trabalha com fatos e formatos controversos, que acabaram de acontecer. Portanto, praticamente, não há perseguições a museólogos, porque geralmente os temas expostos nos museus já são história, foram legitimados, se não pela história, pelo tempo. São os museus da independência, da república, da moeda, da cadeira, de Picasso, de Rembrandt, da capoeira, da música etc. As histórias que os museus contam podem ser factuais, porém sem o compromisso com o que se considera novidade. O museu, geralmente, está associado ao passado, ou ao futuro. $O$ presente dificilmente pode ser produzido e apresentado em tempo real nos museus. Nos meios de comunicação, o objeto é a notícia que está associada ao presente. Conforme Park (2008), a notícia mantém o status de notícia até chegar ao seu destino, às pessoas, quando, então, passa a se constituir história.

Nada disso significa que não haja restrições, inviabilizações e falta de verba ou de interesse direcionados a temas e à criação de museus. O maior museu sobre a cultura e a história das populações que vieram da África, no Brasil, situa-se em São Paulo, montado em 2004. O Museu Afro-Brasil foi concebido por Emanoel Araújo, um negro baiano que também viabilizou o museu Palacete das Artes, que ocupa uma edificação de estilo eclético, típica da virada do século 19 para o 20, no bairro da Graça, em Salvador. Sob intensa polêmica, este museu nasceu como única filial do Museu Rodin fora da França. Assim, podemos entender que no campo dos museus também se instala a espiral do silêncio, com contornos semelhantes aos da Teoria de Noelle-Neumann, relacionada às supressões de abordagem de assuntos, o que seria exatamente o oposto da saliência, que é o indicador do destaque alcançado por determinado tema nas agendas da mídia e do público (Wolf, 2005).

É preciso ressaltar que "informação" e "comunicação" remetem a fenômenos sociais e são apropriadas pela mídia, como suporte organizacional, integrando-as às suas lógicas - econômica, como empresa; tecnológica, como difusão; e simbólica, servindo à 
"democracia cidadã" (Charaudeau, 2009, p. 15). Assim como as mídias típicas do jornalismo, o museu é um espaço público e um produtor de sentido e, por conseguinte, de debate, na medida em que produz sentido e o dissemina. O debate ocorre a partir dele mesmo e do meio que o agenda, ou melhor que torna o assunto saliente. E o espaço público não é somente um local em que se produz sentido. É também o local de construção de opinião (Charaudeau, 2009). O museu oferece informação e obviamente comunica. Pode ser considerado uma instituição de comunicação de massa, mas não na mesma proporção que os meios jornalísticos. É um local de mediação, e inclusive de formação de opiniões.

Os media de massa não monopolizam o fluxo da informação que recebemos nem intervêm em todas as nossas relações sociais alargadas, mas a sua presença é inevitavelmente muito persuasiva (McQuail, 2003,). Os meios de comunicação de massa estão quase que de forma intermitente no dia a dia, são parceiros, são coadjuvantes, e vão adquirindo autonomia. "Na cultura contemporânea, mediadores não-humanos (objetos inteligentes, computadores, servidores, redes telemáticas, smart phones, sensores etc.), nos fazem fazer (nós, humanos) muitas coisas [...]", diz Lemos (2013, p. 19) em sua introdução sobre a Teoria Ator-Rede (TAR), de Bruno Latour. Já em um desdobramento do que foi colocado por Eco (1968) anteriormente.

Com o museu real, que é o que não é o virtual, quem quiser interagir da forma como foi concebida a relação, terá que ir aonde ele está. Nem as fotografias, nem as possibilidades da comunicação digital, são capazes de substituir este movimento de ida ao museu. Podem-se utilizar das novas tecnologias para expor e potencializar a precisão de sua abordagem, entretanto, ainda assim, o fruidor terá que se deslocar até o museu para se envolver com a aura que ele produz. Como é um mix de fragmentos transpostos para um ambiente previamente designado, o objeto exposto no museu real acaba se desviando da concepção prevista da indústria cultural e se mantém particular, único. García Canclini (2003, p. 169) diz que se o patrimônio é interpretado como um repertório de tradições 
representadas pelos objetos, o museu que o expõe precisa ser um "palco-depósito" que seria também um "palco-vitrine". O museu seria este local solene onde seria guardado e celebrado o patrimônio, conforme o regime semiótico decidido pelos grupos hegemônicos. "Entrar em um museu não é simplesmente adentrar um edifício e olhar obras, mas também penetrar em um sistema ritualizado de ação social" (García Canclini, 2003, p. 169).

\section{Ação como mídia}

Como mídia, o museu seleciona o conteúdo que vai manter exposto, em saliência, como na agenda-setting, ou como se houvesse um processo de gatekeeping (Wolf, 1987, p. 184), ou seja, de seleção, como no jornalismo, que permitisse o trânsito do assunto em direção ao público que o agenda e o coloca em evidência, possibilitando que seja discutido. O museu agenda, ao definir o seu conteúdo. A discussão proposta pelo museu é cuidadosa, aprofundada, exclusiva, particular e esclarecedora. Gomes (2001) diz que uma discussão pode realmente ser considerada debate público somente quando atinge cotas quantitativamente significativas de público, de audiência. "Isso faz com que o debate especializado precise, de algum modo, frequentar a mídia" (Gomes, 2001, p. 72). O museu é "lido" e integrado à comunidade a partir da frequência que obtém. Inclusive, em decorrência da sua frequência na mídia.

García Canclini (2003) defende que as alianças programadas, ou não, com os meios de comunicação de massa e o turismo foram mais eficazes para a difusão cultural que as tentativas dos artistas de levar a arte às ruas. $E$ podemos acrescentar que esta regra continua prevalecendo mesmo com o avanço das redes sociais digitais. A tentativa de levar a arte ao seu público pelas infovias digitais esbarra nas possibilidades do museu que é real, que precisa ser sentido para além das telas de um computador. Mas a publicização do seu conteúdo contribui para o aumento da visitação que propicia o envolvimento do fruidor no 
local da veiculação como requer o ritual próprio do ambiente museal.

Ao mesmo tempo, o museu, um mediador de ideias, culturas e histórias, assim como os meios de comunicação, é um contraponto aos veículos envolvidos na pressa diária de reportar e publicar, cada um mais rapidamente que o outro, quando não medem sacrifícios para buscar a melhor história, que cause o necessário impacto da surpresa, do distinto, do inusitado e da novidade (Galtung \& Ruge, 1965). Porque a mídia dos meios de comunicação compõe o discurso, o relato, colocando em concorrência os assuntos para o agendamento do público. O museu se vale de elementos similares que resultam em um trabalho único, em um construto síntese, na forma de um conteúdo que é compartilhado com o público - surpreendente, distinto, inesperado e que provoca uma experiência inovadora.

Podemos nos referir à comunicação jornalística como uma mídia capaz de publicizar e legitimar uma ação, por ser o jornalismo uma instituição crítica, autônoma e credibilizada. 0 encaminhamento que fazemos é o de que o museu pode atrair um maior número de participantes a partir da comunicação que consiga direcionar para a comunidade. Neste trabalho, o jornalismo aparece tangencialmente, com $o$ intuito de demonstrar a importância de um entendimento mútuo entre campos. Quando se fala em "agendamento" de museu, a associação se faz em relação ao agendamento de visita. Agendamento na Teoria da Agendasetting se refere a uma pauta contínua do objeto a ser salientado pela mídia que se atém ao que considera importante - a pauta do museu terá que ser considerada mais notícia que as demais.

Como o museu, a cidade é a síntese da cultura, o que nos leva a compreendê-la como objeto da percepção dos seus habitantes. Ao arquiteto e engenheiro cabe a execução de modificações no espaço urbano, mas, é o habitante, organizado socialmente - ao introduzir e impor o seu desejo - quem mais interfere nela, no lugar em que vive (Lynch, 1980, p. 13). Em processo contínuo, a cidade está sempre sendo feita e refeita e é 
resultado de interações entre o homem - com a sua cultura - e a paisagem existente, depreendendo-se que a relação entre o homem e onde ele vive é preponderante. Defendendo o mesmo entendimento, García Canclini (2008) critica a transformação da cidade em algo a ser assistido por quem mora nela. Seríamos convocados a sermos espectadores de nossa própria cidade e das outras, mesmo antes de visita-las, ou apenas acessando virtualmente seus simulacros na web. Os museus e os centros históricos seriam redefinidos como lugares de exibição de sua arquitetura ou das operações de recuperação que os tornam atraentes, indiferentemente do que contêm ou representam. "Se chegamos à China ou ao Brasil, não vemos sua urbes nem suas gentes como exóticas porque já vimos cópias delas em muitos países e telas. Além disso porque parte dessas cidades foram redesenhadas pela arquitetura e pelo urbanismo transnacionais" (García Canclini, 2008, p. 72). Também os museus passam por situação semelhante, com entendimentos resultantes da globalização que acaba transportando procedimentos que são aplicados, transferidos, até, aleatoriamente.

Especificamente em relação a museus, tendências se espalham, como o museu dos acidentes sugerido por Paul Virilio, inspirado pelas catástrofes de Three Mile Island e Chernobyl, como exemplifica Garcia Canclini. Auschwitz e Hiroshima já são patrimônio mundial da Unesco. O Museu Judaico de Berlin, projetado por Daniel Libeskind, apareceu como uma experiência sensorial. Entretanto, García Canclini (2008) diz que a atribuição do museu não deveria se restringir a organizar o passado e torná-lo apresentável.

\section{A mídia legitima questões}

Conforme McCombs (2009), o jornal mostra a valoração que faz dos acontecimentos ao dispor suas matérias e reportagens no espaço de sua publicação. Se no topo ou na base da página, com ou sem chamada na capa, por exemplo. Também a repetição de 
assuntos em diversas edições é uma outra pista sobre este mesmo status referente à importância que o veículo decide dar ao acontecimento ou questão que deverá ser debatida a partir deste destaque dado. Tudo isso concorre para caracterizar a saliência do assunto. Os públicos usam essas medições para pensar na sua própria agenda, no que vai ser debatido. E a agenda da mídia passa a ser a do público, por transferência, como prevê a própria Teoria da Agenda-Setting. "Em outras palavras, os veículos jornalísticos estabelecem a agenda pública" (McCombs, 2009, p. 18). Colocar um determinado assunto na agenda pública para suscitar um debate ou até uma ação é o estágio inicial da formação da opinião pública. A discussão se efetiva quando se calculam quantos são a favor, quantos são contra e quanto estão indecisos. Daí a fascinação dos meios pelas pesquisas de opinião, especialmente em momentos de campanhas políticas. E nisso pode se resumir o debate, explica o McCombs.

McCombs (2009) retoma Cohen concordando que os meios de comunicação dizem sobre o que pensar mas não sobre como pensar sobre um tema. $\mathrm{O}$ autor considera em primeiro lugar a tarefa de captar a atenção do público, sendo este o primeiro passo para a formação da opinião pública. Lippman (2008) conclui que o analista da opinião pública precisa reconhecer uma relação triangular que envolve a ação, o humano relacionado a ela e a resposta a essa ação. Está aí a origem do agendamento cujo entendimento foi formulado inicialmente por Lippmann (2008), sem nunca ter denominado o fenômeno. Ele conta que em um momento crucial antes da Batalha de Verdun, durante a I Guerra Mundial, generais discutiam a notícia que deveria sair nos jornais de todo o mundo no dia seguinte. O General Joffre aprovou e o comunicado de 300 palavras se espalhou. Mas também foram feitos informes que nada tinham a ver com a realidade, como na situação que teria ocorrido em torno do Forte Douaumont. Houve o relato francês e o alemão, e um era diferente do outro. Lippman mostra que naquele momento, como na atualidade, as questões referentes à mídia, ao jornalismo, se assemelham. E segue 
relativizando sobre as comunicações privadas, mesmo entre autoridades públicas, que não chegam ao conhecimento de todos, ou seja, não são publicizadas, e que muitas vezes falta precisão na identificação de fontes e na abrangência das identificações de conteúdo. "Quem na verdade disse, ouviu, sentiu, contou, nomeou algo, sobre o que você tem na sua opinião?", questiona Lippmann (2008), demonstrando preocupações que se fazem ainda mais pertinentes no estágio da globalização em que vivemos. Entretanto, é sempre bom lembrar sobre a bifurcação que Charaudeau (2009) propõe, ao elucidar a motivação do meio de comunicação de agendar 0 assunto.

\section{Publicização de ações dos museus}

Em Salvador, as instituições se assemelham em seus entendimentos em relação ao cotidiano, quando se referem ao visitante como resposta à difusão feita pela mídia. Em uma consulta processada em novembro de 2016, a museus situados na capital baiana, a resposta foi clara. A publicização de ações está relacionada à frequência. $O$ aumento da visitação ao museu pode ser sentida quando a ação é objeto de inserção da mídia.

Foi aplicada uma entrevista fechada a dez instituições: Museu Abelardo Rodrigues, Museu de Arte da Bahia (MAB), Museu de Arte Moderna da Bahia (MAM-Ba), Museu de Arte Sacra, Museu Carlos Costa Pinto, Museu Casa do Rio Vermelho, Museu da Misericórdia, Museu Palacete das Artes, Museu Tempostal, Museu Udo Knoff de Azulejaria e Cerâmica. Foram formuladas sete perguntas de forma clara e objetiva, sem margem para respostas evasivas, mas com abertura para justificativas. A entrevista foi feita por e-mail.

Os gestores de todas as instituições entrevistadas concordam que os museus que coordenam se beneficiariam com a publicização e com o agendamento de suas ações pelos meios de comunicação formal. Todos consideraram importante que as ações sejam publicizadas. Nenhum respondeu que os meios não pautam os museus que coordenam. Os representantes do Museu de Arte 
Moderna da Bahia (MAM), do MAB, do Museu de Arte Sacra, do Abelardo Rodrigues e do Tempostal afirmaram que são "pouco" pautados pelos meios de comunicação e, destes, somente o de Arte Sacra não possui uma assessoria de imprensa. Todos responderam que puderam constatar resultados de visitação decorrentes e não decorrentes de publicações sobre suas ações nos meios de comunicação. Todos também concordam que o tema de suas ações têm potencial para serem formatados como notícia e que há uma relação de causa e efeito muito próxima entre abordagem nos meios de comunicação e visitação.

A diretora do Museu de Arte Moderna da Bahia, o MAM$B A$, Ana Liberato, defende que a mídia deveria se interessar pelas ações do museu porque há eventos de interesse. Em sua entrevista, feita por esta pesquisadora, a diretora afirma que os jornalistas precisariam entender mais sobre o assunto e serem informados. Que os profissionais do próprio museu teriam que informar os jornalistas e demais, procurando despertar o interesse. Também, que os museus mereceriam ser pautados não só como notícias efêmeras.

A museóloga do Museu Abelardo Rodrigues, Jorma Souza, afirma que o acervo do museu que representa tem "grande potencial informativo e educativo" e que este aspecto justifica a notícia a ser publicada no jornal. A coordenadora cultural do Museu Carlos Costa Pinto respondeu dizendo que "a área cultural é de interesse da comunidade", para sustentar que o tema dos museus seriam relevantes para serem noticiados pelos meios de comunicação.

A coordenadora geral da Casa do Rio Vermelho exemplificou que em julho de 2016, "em decorrência de grande exposição na mídia, em função dos eventos culturais" em homenagem ao centenário de Zélia Gattai, "o fluxo de visitantes mais que duplicou".

\section{Considerações finais}


A aproximação entre o campo dos museus e o dos meios de comunicação se apresenta como uma forma interdisciplinar de se promover o museu e, também, a comunicação. O mercado das comunicações que mediatiza a maioria das experiências na contemporaneidade, em tempo real e presente, pode reforçar a importância da visita presencial aos museus, porque esta necessidade não pode ser relegada ao passado. O museu, que guarda o passado e vislumbra o futuro, só se realiza com a relação direta que se materializa com visita do público e só assim faz sentido - produz sentido. O museu é a própria produção, ao mesmo tempo em que é mediador e é mídia, assim como as suas obras de arte ou seus objetos históricos.

Com este trabalho, que apenas marca o início de uma investigação, pudemos entender que a instituição do museu se renova e, mesmo assim, se mantém fisicamente apesar das novas tecnologias que pavimentam um outro tipo de visitação, a virtual à distância. A problematização se volta para a valorização destas propostas de transportar os conteúdos e considera-los, a despeito da necessidade de promover a relação entre o público e o museu enquanto instituição catalisadora de uma forma específica de seleção e agendamento de conteúdo, sem nos determos neste momento na consideração sobre o conteúdo do que vem sendo "veiculado".

\section{Referências}

Anico, M. (2006). Patrimônio, museus e representações culturais na contemporaneidade. In: E. Peralta, \& M. Anico (Org.). Patrimónios e identidades: ficções contemporâneas. (p. 93100). Lisboa: Celta.

Augé, M. (1994). Não-lugares, Introdução a uma antropologia da supermodernidade. São Paulo: Papirus. 
Castells, M. (2013). Redes de indignação e esperança. Lisboa: Fundação Gulbenkian.

Charaudeau, P. (2009). Discurso das mídias. (Angela S. M. Corrêa. Trad.). São Paulo: Contexto.

Eco, U. (1968). Obra aberta. (G. Cutolo, Trad.). São Paulo: Editora Perspectiva.

Galtung, J. \& Ruge, M. (1965). The structure of foreign news: the presentation of the Congo, Cuba and Cyprus crises in four Norwegian newspapers. Journal of International Peace Research 1. pp. 64-91.

García Canclini, N. (2008). Leitores, espectadores e internautas. (A. Goldberger, Trad.). São Paulo: Iluminuras.

García Canclini, N. (2003) Culturas híbridas. São Paulo: EdUSP.

Gomes, W. (2001). Opinião pública política hoje - uma investigação preliminar. In: A. Fauto Neto et al. (Org.). Práticas midiáticas e espaço público. (pp. 61-82). Porto Alegre: EDIPUCRS.

Lemos, A. (2013). A comunicação das coisas: Teoria Ator-Rede e cibercultura. São Paulo: Annablume.

Lippmann, W. (2008). Opinião Pública. Petrópolis, RJ: Vozes.

Lowenthal, D. (2004). The heritage crusade and the spoils of History. Cambridge: Cambridge University Press.

Lynch, K. (1980). A imagem da cidade. (M. C. T. Afonso, Trad.). Lisboa: Edições 70.

Martin-Barbero, J. (2009). Dos meios às mediações: comunicação, cultura e hegemonia. (R. Polito \& S. Alcides, Trad.). Rio de Janeiro: Editora UFRJ.

Mccombs, M. (2009). A Teoria da Agenda-Setting: a mídia e a opinião pública. Petrópolis, RJ: Vozes.

Mcquail, D. (2003). Teoria da comunicação de massas. (C. de Jesus, Trad.). Lisboa: Fundação Calouste Gulbenkian.

Park, R. E. (2008). A notícia como forma de conhecimento: um capítulo dentro da sociologia do conhecimento. In: C. Berger, \& B. Marocco (Org.). A era glacial do jornalismo: teorias sociais da imprensa. (p. 51-82). Porto Alegre: Editora Sulina. 
Mary Weinstein

Wolf, M. (1987). Teorias da comunicação. (M. J. V. de Figueiredo, Trad.). Lisboa: Editorial Presença. 